\title{
The human will debate between Western and Yoruba philosophical traditions
}

\author{
PhD Olanrewaju Abdul SHITTA-BEY \\ Post-Doctoral Research Fellow: Department of Philosophy, Uludag University \\ Bursa-Turkey Faculty: Department of Philosophy, Lagos State University \\ NIGERIA. \\ E-mail: tilewa02@yahoo.co.uk; shittabey@uludag.edu.tr
}

\begin{abstract}
Discourse on human will has a long history in Western philosophical tradition; and this discourse remains evergreen with changing subject-matter from one period to another. As a matter of fact, the discourse has significant implications for other intellectual disciplines that advance the course of the human species. In this connection, this paper examines the most recurring debate in the history of the discourse on human will; this paper particularly examines the various controversies that have been generated by the question whether the human will is free or not. The question has serious implications on the way we construe existence in all ramifications. The paper considers the debate within the bounds of two distinct thought systems of Western and Yoruba philosophical traditions. Within the context of Western thought, the paper focuses on doctrines that have evolved in the attempt to address or respond to the question whether the human will is free or not. Within the Yoruba thought system, the paper examines the works of some scholars that have contributed to the discourse on the fundamental question. This paper argues that the question of whether the human will is free or not does not arise in the Yoruba philosophical system. The analytic and phenomenological approaches are adopted in this paper. The analytic approach is important to achieve the twin goal of explanation and clarity of concepts and issues; that is, the approach affords us the opportunity to engage and subject written literatures to critical exposition. The phenomenological approach is significant as an interpretative tool to interrogate oral texts that account for the notion and conception of human will in Yoruba thought system.
\end{abstract}

Keywords: Human Will, Determinism, Non-Determinism, Quasi-Determinism

\section{INTRODUCTION}

In Western intellectual tradition, the dominant discourse on the human will is whether it is free or not to perform its attributed function of initiating deliberate choice and action. In other words, discourse on the human will in Western philosophy has been a debate among thinkers in all fields that constitute body of knowledge since antiquity, and this debate is whether the will is free or not in carrying out its attributed duties.

As a result of the dominance of this discourse on the human will in Western thought, it is important to interrogate the Yoruba thought system on this issue in order to establish the dominant orientation within the culture. Thus, to achieve this aim, it is pertinent to revisit this question as it occurs in Western philosophy in order to rekindle our 
knowledge of it, particularly the nitty-gritty of the discourse. However, a consideration of all the thinkers that have contributed to the discourse in one way or the other is not possible because they are too numerous to be accommodated in this paper; therefore, rather than be concern with individual philosopher's contribution to the discourse, we are concern with the fundamentals that categorized them into various doctrines on the question.

In Yoruba thought system, the question of whether the human will is free or not do not arise, however, this does not mean to say that this important question eludes the people. In fact, from our study and as we hope to demonstrate in contrast with the discourse on the question in Western philosophy, the human will in Yoruba thought is paradoxically ascribe with both free and unfree attributes. That is, response to the question in Yoruba thought takes the form that the paper identified as quasi-indeterminism. By quasi-indeterminism, it means that the human will is as free as it is unfree, as well as possessing the additional attribute of not exhibiting these traits in some circumstances while initiating decisions and actions.

\section{THE QUESTION ON THE HUMAN WILL IN WESTERN THOUGHT}

The doctrines of pre-determinism, determinism, indeterminism, and nondeterminism are popular in Western intellectual discourse on the human will question. Principally, the question that each one attempts to address is whether the human will (as a constituent part of human ontology) is free or not to engage in the act of initiating deliberate choice and action. As a matter of necessity, it is important to re-invigorate this human will question in Western philosophy in order to demonstrate the claim of each doctrine.

Pre-determinism (or fatalism) - this doctrine holds that "human choice and action have no influence on future events, which will be as they will be regardless of whatever we think or do" [1]. This view of pre-determinism suggests one of two things: either that the human will as well as the decision and action to be initiated in the course of existence have been fixed from the beginning of time, or that the human will as ontologically conceived (to be a constituent immaterial make-up of human nature) is totally a misconception.

Determinism (or hard determinism) - this doctrine is of the view that "human actions and choices, without exception, are totally determined" [2]. This is a suggestion that the process of making decisions and taking actions is predictable; that is, a decision does not occur as a first cause, rather it occurs as a result of the pre-existent criteria for a specific decision to be made having been met. Concisely, this doctrine denies that we are either in control or capable of exercising our will freely.

Indeterminism (or soft-determinism) - this doctrine holds that as humans, some of our actions and decisions are functions of human free will, while some others are causally constraint. Cogently stated,

It is only in the human realm that the indeterminist wishes to press his case. Reflex actions are $100 \%$ caused, since with regard to them we are not active but passive; the only area in which universal causality does not hold is in the realm of actions, the things we do. With regard to these actions - or at any rate some of them - no one will ever be able to predict them, no matter how such physiological and psychological knowledge we get about their antecedent conditions, because the causal principle does not apply to them [3]. 
In this submission, it is clear that indeterminism does not argue against determinism completely, but only partially. In fact, indeterminism as shown above delineates the boundary of human actions and decisions that constitute those that can be determined apart from those that are of free will.

Non-Determinism (or freewill-ism) - this doctrine is the "belief in freewill, which amounts to the conviction that...human beings are endowed with the capacity for choice of action, for decision among alternatives, and specifically that, given an innate moral sense, man can freely discern good and evil" [4]. As it appears, the doctrine favours absolute freedom of the human will, wherein the will is not restrain in any form or capacity from initiating decision and action.

In other words, supporters of non-determinism (or the freewill-ists) affirmed the position that human decisions and actions are autonomous choices among a number of possibilities. Against this background, a fundamental tenet of this doctrine requires humans to be more aware that each and every decisions and actions taking by them are free and deliberate initiatives of their wills, rather than the results of some previous events, decisions or actions.

\section{THE QUESTION AND SOME SCHOLARS ON YORUBA THOUGH}

Articulately, the accounts of most scholars on Yoruba thought with regard to the question whether the human will is free or not clearly show that they are all cases of misplaced articulations; in other words, inherent in these accounts are many wrongs that characterized them, part of which include misapplication of terms, mis-utilization of doctrines, failure to properly appropriate conceptual equivalences in different cultures (in this case the Yoruba and Western cultures), flagrant imposition of categories of one culture unto another, and so on. Each of these wrongs or combinations of any leads any intellectual account to be categorized as a case of misplaced articulation.

A consideration of the works of some of these scholars will vindicate our claim. For a start, the article "The Yoruba Conception of Destiny: A Critical Analysis" by Ali is an important one. In the article, the primary aim of this reputable scholar was to establish that "Ori ... is a quasi-metaphysical entity which authenticates the uniqueness of a person in Yoruba thought" [5]; whether or not he succeeds in this set objective is not an issue for us here, but of paramount concern to us is the incorporation of Western doctrine(s) by this scholar in his analysis.

According to this scholar, he argues that, Ori and the idea of predestination or human destiny as one of the important tripartite elements constituting the nature of a person in Yoruba... implies the idea of causal explanatory paradigm in relation to human personality in Yoruba thought and this give rise to several conceptual problems such as the paradox of the alterable and unalterable destiny [6].

In the submission above, one will discover that there is a clear problem of conceptualization; first is that Ali takes ori in Yoruba thought to be identical with the idea of destiny as it appears in Western thought. Contrary to this view, ori is not identical with destiny rather it is only a bearer of destiny [7]. The second problem, which is most important in this paper, is that the scholar seems to assume one of two things: (1) that the concept of the human will eludes the Yoruba people, therefore, there is no need to demonstrate whether there is a will or not in Yoruba thought or (2) that the idea of human will is implicit in the idea of Ori in Yoruba thought.

As a result of conceptual problem that arise as shown above,

Ali therefore posits that, 
However, I maintained that the idea of causal determinism suggested by the Yoruba notion of destiny... is not a rigid one that makes human destiny autobiographically or naturally unalterable. Rather, it is an explanatory paradigm which coheres with the reality of responsibility, freewill and the use of reasoning faculty" [8].

In line with this position, Ali clearly posits that,

I propose and defend the claim that the Yoruba are better seen as soft-determinists rather than determinists or fatalists as some scholars on African studies would want us to believe [9].

In another article titled "African Conception of Man and the Paradox of Alterable and Unalterable Destiny in Yoruba Metaphysics", Ali posits that,

In the final analysis, it is argued that the Yoruba people, given their paradoxical notion of human destiny, are freewill-ists. They are because their conception of human destiny regards freedom as well as reason as two features which are not only immanent in the nature of man but are also basic to the survival of man and the actualization of human destiny [10].

In placing the two articles by the same author side-by-side, one obvious problem that catches any one's attention is the claims that the Yoruba system of thought favours soft determinism (indeterminism as explicated at the beginning of this paper) in the first and freewill-ism (non-determinism) in the second. This inconsistency as regard where the Yoruba stands in respect to the question as treated in Western philosophy must have been largely due to what the scholar himself identified as the "Paradox" in Yoruba thought.

On the part of this scholar, his inconsistency started with his failure to properly identify the Yoruba equivalent of the human will. In addition to this, the scholar employs Western concepts and terms unmitigated to interrogate the Yoruba worldview that is originally characterized by paradoxes.

In particular, the scholar thoughts that ori is or embodies the human will. In fact, the scholar holds this idea and thinks that it is not necessary to actually investigate whether the Yoruba have any conception of human will separate from ori or as a constituent attribute of ori itself. Without any iota of ambiguity, we can see clearly why the contribution of this scholar, operating from a Yoruba perspective, cannot but be regarded as misplaced articulation having contributed to the question on whether the will is free or not.

The articles of Balogun are also of utmost interest to our present exercise. The first is titled "The Concept of Ori and Human Destiny in Traditional Yoruba Thought: A Soft Deterministic Interpretation" and the second is titled "Ori as the Sole Determinant of Human Personality in Traditional Yoruba African Thought".

In the first article, the author's principal concern and aim was "to establish and strengthen the argument that the Yoruba are soft-determinists in their understanding of and belief in, the concept of ori and human destiny" [11]. How far he achieved this aim may not be as important as the arsenal of Western categories he deploys to interrogate the Yoruba thought on issues of ori rather than the human will.

At the outset, the scholar appears he was going to demarcate the boundary between discourse on the human will and that of ori in Yoruba thought when he supposes that "ori which is of immediate concern to us in this paper, represents the individuality element in a person" [12]. This sounds very much like an attempt to delineate between ori and the human 
will in Yoruba thought, and this continue to be the case that he even got to a point that he asserts that "ori has nothing to do with moral character, and as such it does not affect all of human actions and/or inactions, in fact, nowhere in any of the ancient Yoruba scriptures is there the claim that moral character can be pre-determined by ori" [13]. Without any further articulation, this goes to show that the author is at the point of separating issues of ori from that of the human will in order to appropriately employ the Western categories of fatalism, determinism, hard-determinism, soft-determinism, and freewill.

However, it is not the case that he actually did what was expected in subsequent paragraphs and pages of the paper, instead he fashions the rest of the article in a manner to also fall into the pit of the evil that we have called misplaced articulation. This misplacement begins to rear its head when the author submits that "the Yoruba posit the concept of afowofa... as explanation for some of the problems that befall a person" [14].

Whatever he meant to say here, we must acknowledge that it is true of the Yoruba people to talk about afowofa (self-caused); but the author himself fails to realize that afowofa do not just happen and more so it is a descriptive word to capture the consequence(s) (particularly negative) of one's deliberate decision and action initiated by one's human will. That is, without the human will which initiates action and decision in a person, any discourse on afowofa among the Yoruba people will not arise, this is because the concept of afowofa is an indication that a person's will must have led the person to a situation or condition that is described as afowofa by the Yoruba people.

Furthermore and most importantly, the author posits that,

The Yoruba traces the course of some events to the individual person who performs the action and not any supernatural force outside of man. Such actions are located in the realm of natural and are empirically observable. It is for this reason that people are punished for wrongdoing because they are believed to be responsible for their actions. This then suggests that in the analysis of the concepts of ori or destiny, the Yoruba falls within the gamut of what is called 'soft-determinism' in metaphysical terms. The nature of ori and human destiny in Yoruba belief is neither fatalism in the strict sense of it, nor hard determinism. The Yoruba conception of human destiny is indeed soft-deterministic in nature [15].

Glaringly, this submission shows that the author himself qualifies the entire contents of his article as misplaced articulation. The first thing we should observe from the above is that in the thinking of this scholar, just like in the thinking of the scholar we considered first, the Yoruba concept of ori is synonymous with the Yoruba conception of the human will. Here, we think this is what is largely responsible for the misuse and misappropriation of Western notions (or metaphysical terms as he calls them) of determinism, fatalism, softdeterminism and so on.

Although, outside this glaring fact of misconception about ori and the human will, one would have expected this scholar to be conscious of how these Western categories should apply; in other words, the way the scholar sets out to achieve his aim, not minding the title of the paper, one should have expected that he should be aware that discourse on any of the Western terms of determinism, indeterminism, soft-determinism, hard-determinism, and fatalism in relation to human species is a discourse on the human will. 
We now turn to the second article by Balogun, because it "is a follow up" [16] to the first. And in this article, his thesis is to defend the position that "it is the combinations of the functions of "ori", "okan" and "ese" that jointly determine and constitute human personality in Yoruba thought" [17].

In the course of the article and in spite of stumbling on Kola Abimbola's submission that "discussing 'ori' (Inner head) in relation to moral responsibility and autonomy as some scholars have done is misplaced" [18]. Having stumbled on this assertion, Balogun would have retraced his steps from further misplaced articulations. That is, the assertion by Abimbola quoted by Balogun as stated above is a clear and enough pointer to demonstrate that discourse on determinism, indeterminism and the likes in relation to ori instead of the human will in Yoruba cultural belief is misplaced.

In sum, it is important to be emphatic that the works of the two scholars that have been considered here (and others not considered) on the issue of whether the human will is free or not in Yoruba thought, vis-à-vis the Western categories of determinism, indeterminism and so on, are so classified to be misplaced on the following grounds:

1. None of them demonstrate to have a clear understanding of the Yoruba conception of the human will.

2. No one among them thinks of dichotomizing, or that there is a dichotomy, between ori and the human will in Yoruba thought system.

3. By extension, all of them confuse the ontological nature, status, and function of ori and the human will as synonymous.

4. Each one mis-utilized Western terminologies to interrogate an important concept in Yoruba thought; they also imposed these terminologies in their exploration of Yoruba thought on the human will question.

On this note, the totality of their explorations take the direction that is worthy of the label mis-placed articulations. We shall move to the next business where we do an investigative and interpretative articulation of the Yoruba traditional worldview concerning the question whether the human will is free or not in the proper performance of its function of initiating deliberate decisions and actions in the human person.

\section{YORUBA INDIGENOUS KNOWLEDGE SYSTEM AND THE QUESTION}

Somewhere above, we have shown that the word afowofa (self-caused) is descriptive in the sense that it is employed in Yoruba estimation to convey the negative consequences of choices arising from any individual's human will. This simply indicates that Yoruba thought system favours the position that the human will is absolutely free, which is non-determinism in Western philosophy. This is evident among the Yoruba with proverbs like:

Boti wu oloju ni i se oju e, translates as One handles one's eyes as one so desires and

A kii pe ki omode ma d'ete, b'oba ti le da igbo gbe translates as No one should stop a child from having leprosy, such child only need to be ready to reside in the forest

These proverbs clearly advocates the Yoruba belief in non-determinism because each reveals the exercise of freewill by individuals; in fact, the second proverb clearly enjoins one to exercise one's freewill with readiness to take responsibility for the consequence(s) of one's actions and decisions. If the consequence(s) of one's actions/decisions turn out to have negative effect on one, this is where the idea of afowofa is used to describe such effect on one. 
Further supporting the view that the Yoruba belief on the human will question is non-determinism, the odu ifa Obara ofun [19] gives credence to this in its rendition that,

Ahere oko a b'idi jeere jeere

Agbalagba ejo ni i fi idobale ara re wo'le

D'ifa fun Babalawo meta

A bu fun Olumoran mefa

Nje ta ni agba

Translate in English as

Imoran ni a nko da, ki a to da Ifa

The hut in the farm with a big buttock

Old snake debases itself crawling

Divined for three Babalawos

Divined for six clairvoyants

The day they staged a superiority contest in Ile Ife

Who is superior?

Ifa is superior

Decision must be made first before one consults Ifa

The above $o d u$ is a clear demonstration that the Yoruba thought system on the question is better classified as non-determinism, especially considering the last line of the $o d u$ which states that decision must be made first before one consults ifa.

However, there are evidences that suggest that the thought system of Yoruba tradition also favours any one of pre-determinism, determinism, and indeterminism, that is, evidences abound in Yoruba worldview that present the people's thought on the freedom/unfreedom of the human will as favouring any of the other doctrines in the discourse on the human will question in Western philosophy.

As pre-determinism, Yoruba thought supports this doctrine whenever the human will is regarded as a constituent make up of a person which initiates decisions and actions that have been fixed in the pre-existent life of a person. In this connection, a person's will acts the scripts that have been written for an individual in the pre-existent world, in this sense, whatever decision and action initiated by the human will, the outcome will always be what has been written. As evidence, it is common among the people to hear proverbs like:

Riro ni ti eniyan, Sise ni t'olorun translates as A person ponders and thinks, but the almighty acts accordingly

And

Bi a gun ata l'odo, Bi a gun ata l'olo, Iwa ata ko pada translates as If pepper is grinded in the mortal or on the grinding stone, none changes the nature of the pepper.

In these proverbs, we can see that the message convey in each postulates that what will be will be, no matter how hard we endeavour to change the situation. In clear terms, the first proverb strongly admonishes that one's existence is designed to be lived according to the dictates of the designer - the Supreme Being.

In addition to the above, the odu ifa Ika oturupon [20] reveals support for predeterminism in Yoruba belief in its rendition that

Ka sangbo sansan bi aladaa

D'ifa fun ajinife omo Olofin

Ka rin hooho bi eledun

D'ifa fun Sadoyanyan omobinrin Ode Owu 
Tori ki won ma ba a ji mi fe

Mo fi ide werewere se eke ile

Tori ki won ma ba a ji mi fe

Mo fi ide gbaragada se ase ilekun

Won tun wa ji mi fe bee be...

Translate in English as

To clear the land fast

Divined for Ajinife who was Olofin's son

To walk about naked like an axe

Divined for Sadoyanyan, a female citizen of Owu town

To prevent being made love to without my consent

I bolted my doors with studded brass

To prevent being made love to without my consent

I bolted my doors with large studded brass

In spite of those precautions, I was still made love to

In this $o d u$, we can see that all efforts to prevent a situation from happening do not change anything, what is design to happen actually happened.

As indeterminism - the doctrine that the human will initiates some decisions and actions freely while some of its decisions and actions are caused. Yoruba belief also gives support to this doctrine. For instance, the following proverbs articulate indeterminism in Yoruba thought:

Ti a ba wo didun ifon, a o wo r'a d'egun, translates as If we are to consider the sweetness of scratching the skin, we shall have to scratch to the bone.

And

Lehin oku la a je akara itufo, translates as we consume burial's bean-cake only after the death of someone

Clearly indicative in the proverbs above is that individuals are free to act as desired, but that there are factors that limit the exercise of individuals' freedom to act. As a point of clarification, the first proverb indicates that there is a limit to our freedom while the second additionally conveys the message that it is not in our purview to take decisions or actions in some situations.

Furthermore, the odu ifa Ofun Nogbe [21] clearly reveals that the Yoruba thought supports indeterminism. This is so because the $o d u$ shows that at some points in time in this material world, individual will initiates decisions and actions that are caused and at some other points it explores the freedom associated with it. According to this $o d u$,

Ti a ba wi fun ni

Ti a ba gbo

Aye a ma a ye ni

Ti a ba wi fun $n$

Ti a ba gba

Aye a ma a ye ni

Awi igbo

Afo igba

Babalawo ode lo se ifa fun ode

Ode nre gbo ije, eluju ije

Won ni k'oru bo

$\mathrm{Ki}$ o le r'ere mu bo 
Ki o ma mu oti

Keke-l'oju omo ode Egba

Alabaja l'orun omo ode Esa

Porogun matuyeri omo odo oluweri

Oni jaye nre le ijaye

Orogun ile f'awo mi lo mi

Translate in English as

When one is warned

And one listens and accepts the warning

Life will be easy and comfortable for one

When one is warned

And one respects and obeys the warning

Life will be easy and comfortable for one

Refusal to listen

Refusal to heed warning

Ode's Babalawo gave him a fixed ifa medicine

When ode was going to the forest for his usual seven days hunting expedition

He was advised to make sacrifice

So that he would be blessed from the expedition

He was forbidden liquor

Tribal-marks-on-the-face, citizen of Egba

Tribal-marks-on-the-neck, citizen of Ijesa

Porogun matuyeri child of river goddess

Ijaye citizen is going back to Ijaye

Senior wife revealed the secret of my true identity

In support of determinism - the view that all our actions and decisions are the results of previous knowable causes, Yoruba belief also demonstrates support for this with proverbs like,

Aiku ekiri, a o ko le fi awo re se gbedu, translates as Without the death of Ekiri (a kind of animal), no one uses its' skin to construct the gbedu (a kind of drum)

And

Adaniloro f'agbara ko ni, translates as The wickedness suffered by someone make one a stronger person

These proverbs advance the message that individuals' conducts and decisions derive from determinable causes. This is especially so in the case of the second proverb because it is impregnated with the idea that the effect of been strong results from the cause of the wickedness that one suffers in the hands of others. Also in support of this view, the odu ifa Ogunda irete [22] speaks thus,

Kukunduku a b'ewe gerugeru

Opo oogun a gun' mo galegale

Bi o ba l'opo oogun, bi o ba l'eke

Eke o ni je o je

Inuire je ju ewe lo

D'ifa fun Ooni Alanak'esuu

Eyi ti ko gbudo ko ohun ifa sile

Translate in English as 
Sweet potato with fresh leaves

Possession and knowledge of too many charms and spells intoxicate

If you have potent charms and spells and you are dishonest

Your dishonesty will render the charms and spells impotent

Honesty and goodwill work better than charms and spells

Divined for the king Ooni Alanak'esuu

Who must follow ifa's advice and injunctions.

We can see that the Yoruba thought is so rich that it also gives support to determinism as a metaphysical doctrine in the human will question. On this note, we may go on and on providing evidences in Yoruba thought that support any of these doctrines in Western philosophy on the question whether the human will is free or not; and this may lead any onlooker to conclude that the cultural thought of the people on the issue is inconsistent.

We must point out that it is not a crime if a cultural intellectual tradition is embedded with evidences and supports for multiple doctrines to an issue. The idea of personhood (see Makinde [23], Akintola [24], Oladipo [25], Awolalu \& Dopamu [26], Abimbola [27], Idowu [28], and others) in Yoruba thought has a useful purpose to serve in this sense: the conception as well as freeness/unfreeness of the human will in Yoruba thought remains salient and paradoxical in this worldview.

The above observation notwithstanding, there are evidences in Yoruba thought that give credence to all the known doctrines in Western philosophy and; in spite of the fact that initiation of decisions and actions in individuals remains a paradox both in the pre-existent and physical existence of a person, the Yoruba position to the question can best be describe as quasi-indeterminism.

By quasi-indeterminism, this paper is saying that the Yoruba belief argues neither for nor against the (im)possibility of a free/unfree human will, in other words, the Yoruba belief is particularly devoid of this question. This contention is explicitly established by the Yoruba expression that Aditu laiye meaning life is paradoxical (or is a paradox).

The paradoxes of life, as held in Yoruba thought, explains the intermittent shifts of the Yoruba position on the question on whether the human will is free or not or neither. These alternatives on the question of the human will in the material world (even in the preexistent life of man) cannot be found combinable in any of the available doctrines in Western philosophy. Therefore, by quasi-indeterminism, it means that the elements of freeness and unfreeness as well as neither characterized the human will question in Yoruba thought.

\section{CONCLUSION}

We have examined the human will question as it exists in Western philosophy by demonstrating the various metaphysical doctrines that characterized the discourse. We specifically articulated that the human will question in Western intellectual tradition constitutes four main doctrines of pre-determinism (or fatalism), determinism (or hard determinism), indeterminism (or soft determinism), and non-determinism (or freewill-ism).

In the paper, we demonstrated that some of the known contributions to the discourse on the question from the Yoruba perspective are misleading. These contributions are misleading because the scholars that attempted to render the Yoruba belief on the question carry out the exercise by mis-equating the human will with ori in Yoruba thought.

In this connection, we are able to show that the idea of the human will is not elusive in Yoruba thought, therefore, ori is not in any way the Yoruba equivalent of the human will 
(see Shitta-Bey [29] for the Yoruba equivalent and conception of the human will). In sum, the paper showed that the Yoruba belief on the human will question cannot be pinned down to any of the known metaphysical doctrines in Western philosophy, rather the Yoruba belief on the question is best categorized as quasi-indeterminism.

\section{REFERENCES}

[1] Craig, E., "Fatalism' in the Concise Routledge Encyclopaedia of Philosophy. London: Routledge, United Kingdom, 2006, p. 274).

[2] Feinberg, J., Reason and Responsibility. CA: Wadsworth Publishing Company, United States of America, 1989, p. 342

[3] Hospers, J., Philosophical Analysis. London Prentice Hall International, Inc. $2^{\text {nd }}$ Edition, United Kingdom, 1967, pp. $324-325$.

[4] Marcoulesco, I., "Freewill and Determinism', in The Encyclopedia of Religion vol. 5 ed., United Kingdom, 1987, p. 419

[5] Ali, S.A., "The Yoruba Conception of Destiny: A Critical Analysis" in Journal of Philosophy and Development, No. 1, Vol. 1 \& 2, Nigeria, 1994, p. 100.

[6] Ibid

[7] Gbadegesin, S., "Toward a Theory of Destiny" in A Companion to African Philosophy ed. K. Wiredu. London: Blackwell Publishing Ltd., United Kingdom, 2004, pp. $314-315$.

[8] Ali, 1994, p. 100

[9] Ibid

[10] Ali, S.A., "African Conception of Man and the Paradox of Alterable and Unalterable Destiny in Yoruba Metaphysics" in Journal of Philosophy and Development. Vol. 9, Nos. 1 \& 2, Nigeria, 2007, p.48.

[11] Balogun, O.A., "The Concept of Ori and Human Destiny in Traditional Yoruba Thought: A Soft Deterministic Interpretation" in Nordic Journal of African Studies 16(1), Sweden, 2007, p. 117.

[12] Ibid, p. 118

[13] Ibid, p. 125

[14] Ibid, p. 126

[15] Ibid

[16] Balogun O.A., "Ori as the sole Determinant of Human Personality in Traditional Yoruba-African Thought" in Lumina Vol. 21, No. 2, Philippines, 2010, p. 1

[17] Ibid

[18] Ibid, p. 7

[19] Adewale-Somadhi, FAMA, Sixteen Mythological Stories of Ifa. San Bernardino, CA: Ile Orunmila Communications, United States of America, 2009, pp. 55 - 56.

[20] Ibid, pp. $75-76$.

[21] Ibid, pp. $111-112$.

[22] Ibid, pp. $65-66$.

[23] Makinde, M.A., African Philosophy: The Demise of a Controversy. Ile-Ife: Obafemi Awolowo University Press Limited, Nigeria, 2007.

[24] Akintola, A., Yoruba Ethics and Metaphysics. Ogbomoso: Valour Publishing Ventures Limited, Nigeria, 1999

[25] Oladipo, O., "The Yoruba Conception of a Person: An Analytico-Philosophical Study" in International Studies in Philosophy, xxiv/3, United States of America, 1992, pp. 15 - 24.

[26] Awolalu, J.O. and Dopamu, P.A., West African Traditional Religion. Lagos: Macmillan Nigeria Publishers Limited Revised Edition 2005, Nigeria, 1979.

[27] Abimbola, W., "The Yoruba Concept of Human Personality" in La Notion de Personne en Afrique Noire. Colloques Internation aux de centre National de recherché Scientifique, france, 1971.

[28] Idowu, E.B., Olodumare; God in Yoruba Belief. Lagos: Lagos Longman Nigeria Plc. Revised and enlarged Edition 1996, Nigeria, 1962.

[29] Shitta-Bey, O.A., 2014. "Ife-Inu: Equivalent and Conception of the Human Will in Yoruba Thought". Inter-Culture Philosophy: Journal of Philosophy and Its Cultural Context, Issue No. 1, pp. 87 - 112. 